\title{
THE INFLUENCE OF CHELATION ON RADIOMANGANESE EXCRETION IN MAN AND MOUSE ${ }^{1}$
}

\author{
BY LAURENCE S. MAYNARD ${ }^{2}$ AND SIDNEY FINK ${ }^{3}$ \\ (From the Medical Department, Brookhaven National Laboratory, Upton, N. Y.; and the \\ Division of Neoplastic Diseases, Montefiore Hospital, New York, N. Y.)
}

(Submitted for publication August 3, 1955; accepted April 3, 1956)

Manganese is capable of forming complex ions with many substances found naturally in the body (1). It seems reasonable to assume, therefore, that manganese injected as $\mathrm{MnSO}_{4}$ (hereafter referred to as "ionic manganese") will be complexed in the body to a varying extent shortly after administration. If the $\mathrm{Mn}$ is strongly chelated before it is injected, a state of competition between ligands is set up, and an estimate of the strength of the physiological binding of manganese can be gained from the degree of alteration of the natural excretory pattern of the isotope resulting from the use of the strong chelate. In order to test this assumption, manganese was administered after previous chelation with an excess of EDTA ${ }^{4}$ (hereafter referred to as "Mn chelate"), a strong complexing agent which has been shown to have pronounced effects on the excretion of some metals (2). The excretory patterns of "ionic" and "chelated" Mn were then compared.

When injected intravenously into experimental animals, manganese is rapidly removed from the circulating blood and distributed to various tissues of the body (3). The organs having the greatest capacity for manganese uptake are the liver, pancreas, and kidneys: and within the liver cell this element is concentrated to a high degree in the mitochondria (4). Excretion is almost entirely fecal, and more than half of this manganese is eliminated in the bile. Increasing the amount of manganese injected increases the rate of excretion $(5,6)$. An appreciable percentage also appears

\footnotetext{
1 This work was supported by the United States Atomic Energy Commission.

2 Present address : Department of Anatomy, The Johns Hopkins University School of Medicine, Baltimore 5, Maryland.

3 This investigation was conducted during the tenure of a Damon Runyon Memorial Fund Research Fellowship. Present address: GI Section, the Hospital of the University of Pennsylvania, Philadelphia, $\mathbf{P a}$.

4 Abbreviation for the di-sodium salt of ethylenediaminetetraacetic acid.
}

in the pancreatic juice, the level rising and falling together with fluctuations in the enzymatic activity of the juice (7).

\section{METHODS}

$\mathrm{Mn}^{56}\left(\mathrm{t} 1 / 2: 2.59 \mathrm{hrs}\right.$ ) , and $\mathrm{Mn}^{52}$ ( $\mathrm{t} 1 / 2: 5.8$ days) were used as tracers in these studies, the former being prepared in the Brookhaven nuclear reactor, and the latter in the Brookhaven cyclotron. Both isotopes were checked for radiological purity by following the rate of radioactive decay for at least five half-lives, with no significant deviation from the expected rates noted. The subjects received doses of 0.1 to $1.0 \mathrm{mc}$., containing less than 1.0 mg. of $\mathrm{Mn}^{++}$, administered directly into the tubing of a rapidly running intravenous infusion of 5 per cent glucose in water, and washed in with about $100 \mathrm{ml}$. of the solution. In two experiments, the dose was mixed with a 10 to 50 fold excess of EDTA (buffered at $\mathrm{pH} 7.4$ ) prior to administration. Standards for comparison were made at the same time, by preparing suitable dilutions of the injected material. Experimental data are expressed as percentages of the dose administered.

Nine patients were studied, all of whom were considered to have malignant disease, but only one of whom (S. G.) was not ambulatory, and had clinical or laboratory evidence of impaired hepatic function. In none of the patients was there evidence of renal or gastrointestinal dysfunction.

The patient, S. G., had a biliary fistula through which approximately 40 per cent of an estimated $600-\mathrm{ml}$. total daily output of hepatic bile was passed. She had laboratory evidence of severely impaired hepatic function (BSP retention 100 per cent after 2 hrs.), and at autopsy three weeks later was found to have severe biliary cirrhosis.

Samples of heparinized whole blood were drawn at frequent intervals from all patients for up to four hours following injection. In three patients, 24-hour collections of urine and feces were carried out for six days. All of these patients had spontaneous, daily evacuations. In the patient (S. G.) with the external biliary fistula, three trials were carried out, and bile and urine were collected for 24-hour periods.

Counting of specimens and standards was done in a well-type scintillation counter. Samples of blood and urine were counted directly; weighed samples of feces were first homogenized in a Waring blendor, and weighed aliquots were counted. In two patients in whom retention of a large proportion of the dose was suspected, a body 


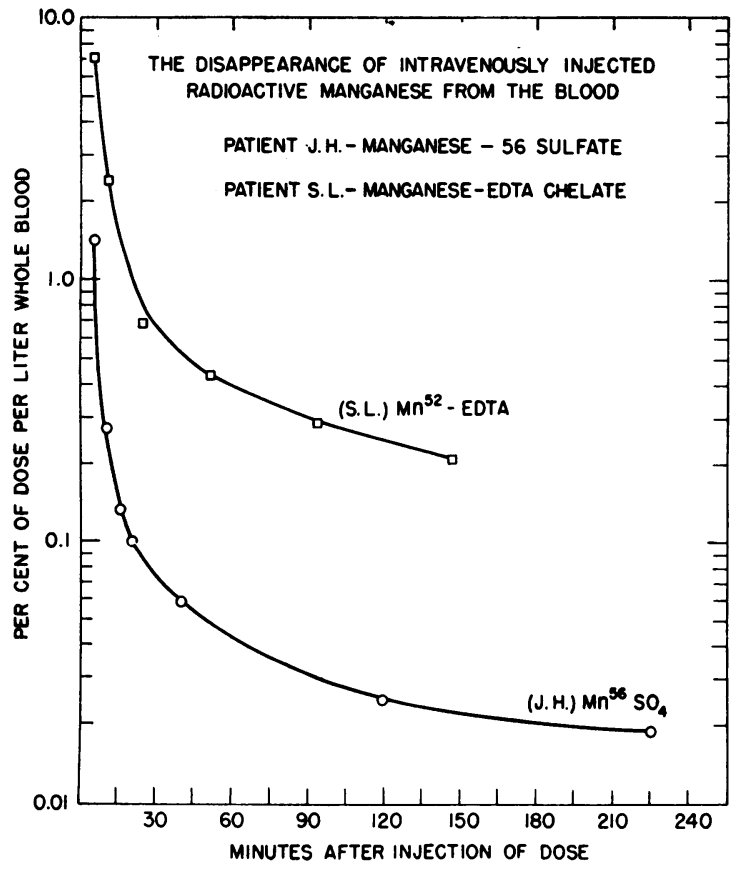

FigURE 1

survey for radioactivity was made seven days after the injection of the $\mathrm{Mn}^{52}$, using a radiation monitor.

Supplementary experiments were carried out with three groups of four white mice each. Each mouse received $0.25 \mathrm{ml}$. of buffered ( $\mathrm{pH} 7.4) \mathrm{Mn}^{\mathrm{s} 2}$ solution intraperitoneally, containing a total of about 500,000 counts per minute. In addition, the three groups received carrier $\mathrm{Mn}$ or EDTA as follows: group 1 (low carrier) 1.0 mcg. $\mathrm{Mn}^{++}$; group 2 (high carrier) $10.0 \mathrm{mcg}$. $\mathrm{Mn}^{++}$; group 3 (chelate) $1.0 \mathrm{mcg}$. $\mathrm{Mn}^{++}$and a ten-fold excess of EDTA. All mice were about $30 \mathrm{gm}$. in weight. At various intervals following injection, the mice were tightly confined in stoppered, ventilated $50-\mathrm{ml}$. lusteroid tubes. The whole mouse was then counted in vivo in a well-type G-M gamma counter, designed for counting large sample volumes. By comparison of the count at any given interval (count at $t$ ) with that obtained immediately after the administration of the dose ( $t$-zero count), making corrections for radioactive decay, the per cent of the dose retained by the mouse at time $t$ could be readily determined. A minimum of twelve measurements was made on each group over a total period ranging from 189 to 240 hours. Seventy per cent to 90 per cent of the dose was excreted during this interval.

This technique does not differentiate between urinary and fecal excretion, but by keeping the counting geometry constant-i.e., carefully positioning and immobilizing the mice-it affords a simple and accurate method of measuring the rate of overall elimination. The results were plotted on semi-logarithmic paper in terms of per cent of dose retained against time, and subjected to statistical analysis.

\section{RESULTS}

\section{Blood levels (Figure 1)}

Ten similar blood curves were obtained in seven patients, which showed rapid decline of the manganese isotope level of the blood in the period following the intravenous injection of the material as $\mathrm{MnSO}_{4}$ in aqueous solution. Two altered curves which, however, resembled each other, were obtained from two subjects following the administration of the Mn-EDTA chelate. Curves from representative patients are shown in Figure 1.

It can be seen that the "ionic" manganese ( Mn in aqueous solution) curve fell more precipitously than did the Mn-EDTA curve, and remained at a lower level throughout the period of observation.

\section{Urinary and fecal excretion (see Table I)}

As shown in Table I, the urinary excretion of administered "ionic" manganese was almost negligible, but increased markedly when given as the Mn-EDTA chelate. The change induced by the chelating agent was immediate but of short duration, with no effect discernible after the second day. The fecal excretion of "ionic" manganese was appreciable, reaching its peak in the second or third day following administration. At the end of the six-day collection period, the radiation survey showed considerable remaining radioactivity, largely in the hepatic area.

\section{Biliary excretion}

In the patient with the biliary fistula a very small percentage of the injected $\mathrm{Mn}$ (average of 3 trials $=0.09$ per cent) was recovered in the bile.

Table I

The Urinary and Fecal Excretion of Radiomanganese in Man

\begin{tabular}{|c|c|c|c|c|c|c|}
\hline \multirow[b]{2}{*}{ Potient } & \multicolumn{6}{|c|}{ Amounts Expressed as Percent of Injected Dose } \\
\hline & $\begin{array}{c}\text { Collection Period, } \\
\text { Days }\end{array}$ & $\begin{array}{l}\text { Trocer } \\
\text { Moterial } \\
\text { Injected }\end{array}$ & $\begin{array}{l}\% \text { of Dose } \\
\text { in Urine, } \\
\text { First Doy }\end{array}$ & \begin{tabular}{|l} 
Total \\
Urinary \\
Excretion
\end{tabular} & $\begin{array}{l}\% \text { of Dose } \\
\text { in Feces, } \\
\text { First Two Doys }\end{array}$ & $\begin{array}{l}\text { Total } \\
\text { Fecal } \\
\text { Excretion }\end{array}$ \\
\hline R. B. & 6 & $\mathrm{Mn}^{32}$ in Woter & 0.45 & 0.74 & 20.5 & 31.4 \\
\hline M. $\mathbf{0}$. & 6 & Mn 32 in Water & 0.21 & 0.23 & 3.15 & 8.4 \\
\hline S. G. & 1 & Mns6 in Woter & 0.13 & 0.13 & - & - \\
\hline s. G. & 1 & Mnse in EDTA & 4.56 & 4.56 & - & - \\
\hline S. L. & 6 & Mn 32 in EDTA & 166 & 16.7 & 0.8 & 6.7 \\
\hline
\end{tabular}

EDTA is Ethylenediamine-tetraocetic Acid 


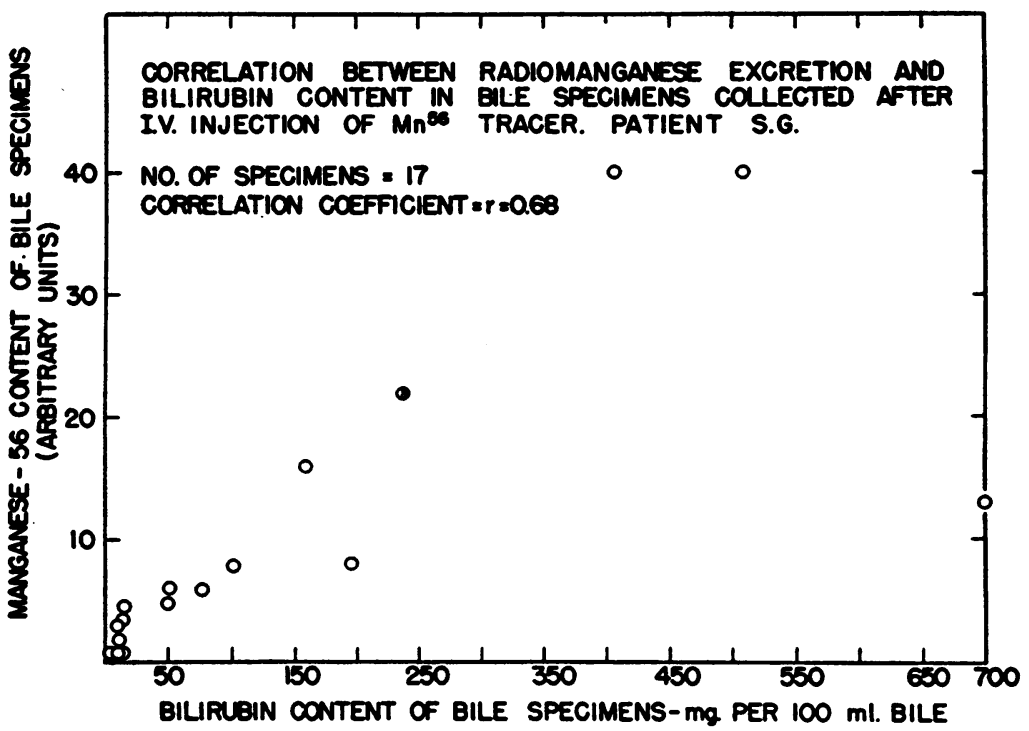

Figure 2

Retention of $\mathrm{Mn}^{32} \mathrm{SO}_{4}$ by Mice $\overline{\mathrm{VS}}$. Time. $1.0 \mathrm{mcg} \mathrm{Mn}+t$ in Doṣe (Low Carrier Group). Four Mice in Group. In Vivo Count Method

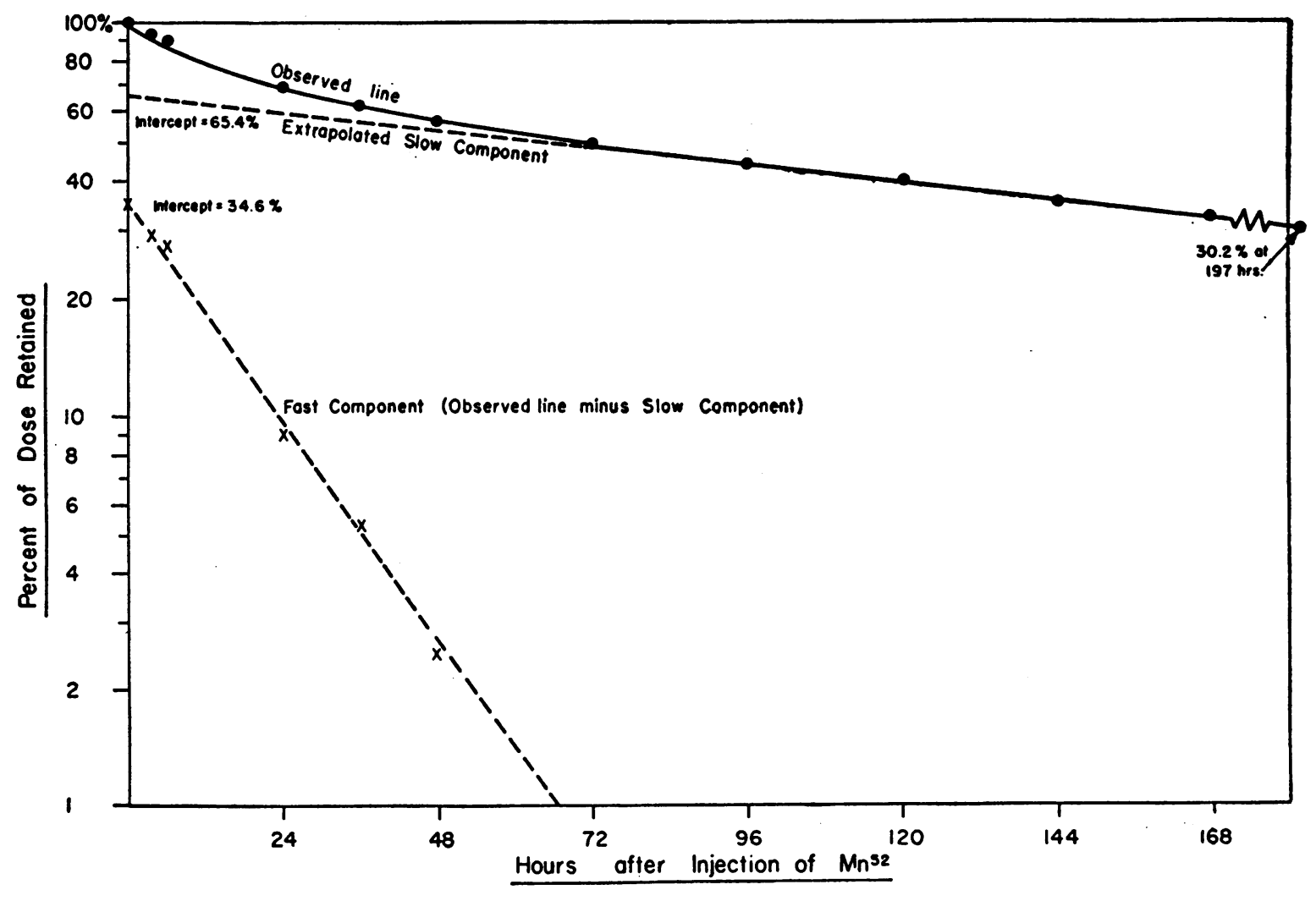

Figure 3 
Table II

Petention of chis by mice

\begin{tabular}{|c|c|c|c|}
\hline Group of wice & $\begin{array}{l}\text { Low Corr'ti } \\
1.0 \mathrm{mes} \mathrm{Mn}\end{array}$ & $\begin{array}{l}\text { Nith Cerriar } \\
10.0 \text { mea Mn }\end{array}$ & 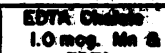 \\
\hline \multicolumn{4}{|l|}{ SLW COMPONENT } \\
\hline Intercept (a) & $65.4 \%$ & $25.2 \%$ & $50.0 \%$ \\
\hline $\begin{array}{l}18 \text { Confidence } \\
\text { Limits of } 0\end{array}$ & $61.1-69.9 \%$ & $21.4-29.5 x$ & $45.5-55.18$ \\
\hline Half - Time $(t / 2)$ & 168.1 hrs. & $130.2 \mathrm{hrs}$. & 204.1 hrs. \\
\hline $\begin{array}{l}\text { T5 Contidence } \\
\text { Limits of } 1 / 12\end{array}$ & 150.3-190.6 hrs. & 108.3 - 163.2 hes. & $170.9-253.3 \mathrm{hrs}$ \\
\hline \multicolumn{4}{|l|}{ FAST COMPONENT } \\
\hline intereept (o) & $34.6 \%$ & $74.8 \%$ & $50.0 \%$ \\
\hline $\begin{array}{l}\text { Ty Confidence } \\
\text { Limits of a }\end{array}$ & $32.4-37.0 x$ & $63.8-87.9 x$ & $44.6-54.0 \%$ \\
\hline Half - Thine (tire) & $13.0 \mathrm{hrs}$. & 9.4 hrs. & $7.6 \mathrm{hrs}$. \\
\hline $\begin{array}{l}18 \text { Confidence } \\
\text { Limule of } t 1 / 2\end{array}$ & 12.1- $14.0 \mathrm{hrs}$. & $6.3-18.9$ hrs. & $6.2-9.9 \mathrm{mrs}$ \\
\hline
\end{tabular}

although 200 to $250 \mathrm{ml}$. was obtained in each trial. This small percentage was not modified in the one trial where $\mathbf{M n}$-EDTA was used. Since $\mathbf{M n}^{\mathbf{5}}$ was used, biliary levels could not be followed for more than 24 hours. It was noted, however, that the great individual variations in $\mathrm{Mn}^{56}$ levels and bilirubin content appeared to coincide (Figure 2). Calculation of the coefficient of correlation gives a value for $r: 0.68$. The probability of such a correlation occurring by chance is $0.0024(8)$.

\section{Manganese excretion in mice}

When the per cent of the dose retained is plotted against time on semi-log. paper, all three groups of mice have $\mathrm{Mn}$ retention curves of similar shape (Figure 3 ). If the straight line segment of this curve is extrapolated back to zero time (by applying the method of least squares to the last six points), and the resulting straight line subtracted from the observed curve in its early portion, a second set of points are obtained, to which a second straight line may be readily fitted. Thus the curve determined by experiment may be analyzed as the sum of two exponential functions, tentatively titled the "rapidly excreted component," and the "slowly excreted component," or, for the sake of brevity, the fast and slow components. The data can be summarized by giving the values of the intercepts and lambdas (logarithmic slopes) for the fast and slow components of each experimental group (Table II). The biological halftimes of each straight line are given for the sake of easier comparison $\left(t^{1} / 2=\ln 2 /\right.$ lambda $)$.

On consideration of the intercepts of the slow components, one can see that when $\mathrm{Mn}$ is chelated with EDTA the value of this intercept falls; and when carrier $\mathrm{Mn}$ is increased ten-fold, the intercept falls even further (Table II). The standard deviations of these intercepts have been calculated (9), and the differences are statistically significant ( $p$ : less than 0.0001).

Small differences are observed in the lambdas (and half-times), but the significance of these is unclear. Therefore, in interpreting these data, our attention will be confined to the difference in intercepts (Table II).

The equations used to compute the standard deviations of the intercepts are as follows :

$$
S_{\log \cdot y \cdot x}=\sqrt{\sum(\log \cdot y-\log . Y)^{2} / N-2},
$$

where $\log . y$ is the observed value of the log. of $y$, $\log$. $Y$ is the $\log$. of the value of $y$ obtained from the fitted line, and $\mathrm{N}$ is the number of points used in fitting the line.

$$
S_{\log . b}=S_{\log \cdot y \cdot x / \sqrt{\mathrm{NBx}^{2}},}
$$

where $S_{x}$ is the standard deviation of the $x$ 's. Conversion of $S_{\text {log. } b}$ from common to natural logarithms (times 2.302585) gives $S_{\text {lambda. }}$

$$
S_{\text {log. a }}=S_{\text {log. } y \cdot x} \sqrt{1 / N+\frac{(x-\bar{x})^{2}}{N_{x}{ }^{2}}},
$$

where $\mathbf{x}$ is the value of $\mathbf{x}$ at which a (the intercept) is determined; in this case, zero; and $\bar{x}$ is the mean value of the $x$ 's.

\section{DISCUSSION}

Comparison of the blood curves for "ionic manganese" with those for the "Mn-chelate" shows a similar configuration in both curves, but a greatly reduced overall rate of movement out of the blood stream for Mn-EDTA.

The data presented in Table I suggest that the primary pathway of "ionic" manganese excretion in man is fecal, as is the case in experimental animals. Urinary excretion appears to be negligible.

When the Mn-EDTA chelate is administered, however, a significant percentage of the tracer dose appears in the urine during the first 24 hours, with concomitant suppression of fecal excretion. Following this period, elimination in the feces is resumed, and the urinary $\mathrm{Mn}$ falls to a negligible level.

The biliary excretion data, although inadequate 
to give any quantitative estimates of the relative importance of this route in man, does offer a suggestive correlation between the $\mathrm{Mn}$ and bilirubin content of the specimens. The possibility that a Mn-bilirubin complex may indeed play an important role in the excretion of this element is supported by some data obtained by the ion exchange technique for measuring the formation constants of complex ions (10). At $\mathrm{pH} 7.4$ and an ionic strength of $0.16 \mathrm{M}(\mathrm{Na}+)$-approximately physiological conditions - the formation constant of a Mn-bilirubin complex was found to be $K_{\mathrm{f}}: 1700$. In contrast, a representative bile acid (cholic acid) showed no measurable complex forming ability. For comparison, $K_{f}$ values for $M n$-citrate: 2900, and Mn-EDTA: $1.7 \times 10^{7}$ were determined under the same experimental conditions. The adenosine polyphosphates, plasma proteins, and some other physiologically active substances also proved to be able to complex manganese $(1,11,12)$.

The experimental data suggest that, after injection, Mn follows at least two metabolic pathways. These findings can be explained by the assumption that one portion of the dose is quickly and strongly bound in the body, and therefore slowly excreted, while a second fraction is unbound (or weakly bound), and rapidly excreted. If this hypothesis is valid, it can be anticipated that the unbound fraction would become chelated with EDTA and rapidly lost in the urine, while the strongly bound fraction would largely remain uninfluenced by this agent, and follow the pattern of elimination seen in the absence of EDTA. Review of both the human and mouse data (Tables I and II ; Figure 3) supports this assumption.

The hypothetical kinetics described above could be further modified in the body, and the effects of EDTA lessened, by other competing divalent ions such as calcium or magnesium, which could form complexes with the EDTA in the dose. Such an effect is probably minimal, since the formation constant of the Ca-EDTA complex is many orders of magnitude smaller than that for Mn-EDTA. The Mg-EDTA formation constant is even smaller (1).

This hypothesis of multiple metabolic pathways was first suggested by the two patients (R. B. and M. D.) in whom the excretion of "ionic" Mn was followed. In these subjects, fecal excretion reached a peak on the second day (Table I), and then slowed markedly. Confirming this suggestion, the mouse studies showed $\mathrm{Mn}$ retention curves which can be readily analyzed into fast and slow components (Figure 3 ).

Likewise, consideration of these same two patients (R. B. and M. D.) permits some speculation about the effects of additional carrier on $\mathrm{Mn}$ excretion. R. B. received about 40 times as much Mn (0.66 mg.) as did M. D. (0.017 mg.), and during the six days of observation $\mathrm{R}$. B. excreted 31.4 per cent of the dose, while M. D. excreted only 8.4 per cent. It would appear that the rate of excretion is increased as more carrier is given. Such a phenomenon has been previously observed in rats $(5,6)$. On the basis of the multi-component hypothesis, one would anticipate that this increase in the rate of excretion would be due to an increase in the proportion of the total dose being eliminated via the unbound, rapidly excreted components. From the mouse data, one finds (Table II) that a ten-fold increase in carrier raises the intercept of the rapidly excreted component from 34.6 per cent to 74.8 per cent, as predicted.

The effects on excretion kinetics of increasing the amount of carrier $\mathrm{Mn}$, and that of pre-chelation of Mn with EDTA, may be readily explained by this hypothesis. In both instances the effect appears to be one of increasing the proportion of $\mathrm{Mn}$ excreted in the rapid component. It seems plausible to assume that the manganese binding capacity is limited, and therefore that additional carrier $\mathrm{Mn}$ would be shunted into the rapidly excreted fraction, and have little influence on the slowly excreted, bound fraction, which presumably has been saturated. A strong chelating agent, such as EDTA, would act by competing with the bound fraction for the available $\mathrm{Mn}$, and sequestering some of it. Since EDTA itself is rapidly excreted (1), the Mn bound by it would appear in the rapidly excreted fraction. The increase in the fast component produced by this means would have an inverse relationship to the strength of the physiological mechanism for Mn binding.

\section{CONCLUSIONS}

1. The kinetics of manganese excretion were studied in man and in mice following the intravenous injection of a radioactive tracer. 
2. Rapid removal of manganese from the circulating blood occurred, and slowing of this removal after pre-chelation of the dose with EDTA was observed.

3. Manganese excretion in the patients studied was primarily fecal. When pre-chelated with EDTA, Mn is eliminated almost exclusively in the urine for about 24 hours, and then fecal excretion is resumed.

4. Excretion curves obtained from mice could be analyzed graphically into fast and slow components. Increasing carrier $\mathrm{Mn}$, and pre-chelation of $\mathrm{Mn}$ with EDTA both increased significantly the intercept of the fast component.

5. It is suggested that the degree of influence on the excretory pattern of manganese exerted by pre-chelation with EDTA is an inverse function of the degree and type of physiological binding of this element.

6. It is suggested that the observed behavior of manganese is best explained by assuming the existence of bound and unbound fractions in the body.

\section{ACKNOWLEDGMENT}

The authors wish to express their gratitude to Dr. George C. Cotzias, Medical Department, Brookhaven National Laboratory, whose comments and suggestions were of great assistance in interpreting our data; and to Dr. Margaret Merrell, Department of Biostatistics, Johns Hopkins University School of Hygiene and Public Health, who advised us on the statistical analysis of our data.

\section{REFERENCES}

1. Martell, A. E., and Calvin, M., Chemistry of the Metal Chelate Compounds. New York, Prentice Hall, Inc., 1952.

2. Hart, H. E., Greenberg, J., Lewin, R., Spencer, H., Stein, K. G., and Laszlo, D., Metabolism of lanthanum and yttrium chelates. J. Lab. \& Clin. Med., $1955,46,182$.

3. Walbum, L. E., and Schmidt, S., Die Bedeutung der Metallsalze für die Ambozeptorbildung. Ztschr. f. Immunitätsforsch. u. exper. Therap., 1925, 42, 32.

4. Maynard, L. S., and Cotzias, G. C., The partition of manganese among organs and intracellular organelles of the rat. J. Biol. Chem., 1955, 214, 489.

5. Greenberg, D. M., Copp, D. H., and Cuthbertson, E. M., Studies in mineral metabolism with the aid of artificial radioactive isotopes. VII. The distribution and excretion, particularly by way of the bile, of iron, cobalt, and manganese. J. Biol. Chem., 1943, 147, 749.

6. Bruner, H. D., Personal communication, 1955.

7. Burnett, W. T., Jr., Bigelow, R. R., Kimball, A. W., and Sheppard, C. W., Radiomanganese studies on the mouse, rat and pancreatic fistula dog. Am. J. Physiol., 1952, 168, 620.

8. Treloar, A. E., Sampling errors of the correlation coefficient in Biometric Analysis, An Introduction. Minneapolis, Burgess Publishing Co., 1951, Chapt. 17 , p. 207-214.

9. Schultz, H., The standard error of a forecast from a curve. J. Am. Statistical Assn., 1930, 25, 139.

10. Schubert, J., Ion-exchange studies of complex ions as a function of temperature, ionic strength, and presence of formaldehyde. J. Phys. Chem., 1952, $56,113$.

11. Maynard, L. S., Unpublished data.

12. Maynard, L. S., Brookhaven National Laboratory Quarterly Progress Report, Jan. 1-Mar. 31, 1955, Unclassified Section, BNL 337 (S-25), p. 52.

\section{SPECIAL NOTICE TO SUBSCRIBERS}

Post Offices will no longer forward the Journal when you move.

Please notify The Journal of Clinical Investigation, Business Office, 622 West 168th Street, New York 32, N. Y. at once when you have a change of address, and do not omit the zone number if there is one. 